\title{
Poly[oligo(oxyethylene) methacrylate-co-sodium methacrylate] as a Polymeric Solid Electrolyte with Sodium Ionic Conduction
}

\author{
Norihisa KoBAYASHI, Takashi HAMADA, Hiroyuki OHNO, \\ and Eishun TSUCHIDA* \\ Department of Polymer Chemistry, Waseda University, \\ Tokyo 160, Japan
}

(Received April 3, 1986)

\begin{abstract}
Poly[oligo(oxyethylene) methacrylate-co-sodium methacrylate] was prepared as a polymeric solid electrolyte which enables sodium single ionic conduction. A methanol solution of the mixture of oligo(oxyethylene) methacrylate and sodium methacrylate was cast and polymerized on a Teflon ${ }^{\circledR}$ plate. The film obtained showed a conductivity of $4.0 \times 10^{-7} \mathrm{~S} \mathrm{~cm}^{-1}$ at $80^{\circ} \mathrm{C}$. The conductivity of the films depended on the sodium methacrylate content. Temperature dependence of the conductivity was analyzed as WLF-type behaviour. The ionic conduction mechanism of this film was found to be deeply affected by the segmental motion of the matrix polymer. This was also confirmed by the Vogel-Tammann-Fulcher plot for ionic conductivity.

KEY WORDS Polymeric Solid Electrolyte / Sodium Conductor / Dissociation Energy / Thin Film / WLF Behaviour /
\end{abstract}

Polymeric solid electrolytes with high ionic conductivity and good processibility are in serious demand for the development of electronic devices. ${ }^{1-3}$ Many investigations in this field have been carried out, especially on poly(oxyethylene)-alkali metal salts systems. $^{4-13}$ The authors have prepared polymeric solid electrolytes to satisfy the following requirements, ${ }^{14-18}$ (1) construction of flexible polymer domain in which let carrier ions exist stably, (2) decrease of the $T_{\mathrm{g}}$ of polymer solid electrolyte in order to increase the mobility of carrier ions, and (3) inhibition of the migration of counter ions. Polymeric solid electrolytes reported previously have already satisfied requirements, (1) and (2). However, the last one (3) has not always been satisfied. A secondary solid-state battery or some application of the solid electrolytes required no anion migration because that caused a serious self discharge. A few approaches for the single-ionic conductor were carried out with Poly[oligo(oxyethylene) methacrylatelithium methacrylate] system, ${ }^{18}$ high molecular weight PEO and polyelectrolyte blend system, ${ }^{19}$ or low molecular weight PEO and polyelectrolyte blend system. ${ }^{20} \mathrm{We}$ also reported the lithium polymeric solid electrolyte with single-ionic conduction, and the solidstate battery composed of this has been evaluated. ${ }^{18}$ As lithium is more expensive than sodium for the application to commercial battery, the sodium single-ionic conductor should be requested. Furthermore, the redox potential of sodium is similar to that of lithium and costs less.

In the present paper, poly[oligo(oxyethylene) methacrylate-co-sodium methacrylate] was prepared as a polymeric solid electrolyte by sodium ionic conduction.

* To whom correspondence should be addressed. 


\section{EXPERIMENTAL}

\section{Materials}

Sodium Methacrylate. A known amount of reagent-grade sodium hydroxide was neutralized with a large excess of distilled methacrylic acid in dry methanol at $25^{\circ} \mathrm{C}$ for $2 \mathrm{~h}$. Sodium methacrylate (MANa) obtained was precipitated by pouring this methanolic solution into dry acetone. The white precipitate was dissolved again in methanol and reprecipitated from dry acetone three times. It was then washed with dry acetone several times and dried in vacuo at $40^{\circ} \mathrm{C}$ for $15 \mathrm{~h}$. No contamination by free acid was confirmed by IR spectroscopy.

Oligo(oxyethylene) Methacrylate. Oligo(oxyethylene) methacrylate $\left(\mathrm{MEO}_{n} ; n=7, n\right.$ : number of oxyethylene unit of the side chain) was prepared and purified according to the method previously described. ${ }^{17}$ Oligo(oxyethylene) monomethylether with an average number of repeating units of 7 (Aldrich Chem. Inc.) was reacted with a large excess of metallic lithium by refluxing with dry THF for three days under an inert atmosphere. After the removal of unreacted metallic lithium, a dry THF solution of an excess amount of methacryloyl chloride was slowly added to the solution at $0^{\circ} \mathrm{C}$. The mixture was reacted for $10 \mathrm{~h}$ at $0^{\circ} \mathrm{C}$, then at room temperature for another day. The resulting mixture was carefully concentrated by evaporation at a temperature lower than $30^{\circ} \mathrm{C}$, then the solvent was replaced the dry chloroform. Complete evaporation while replacing the solvent should be avoided; otherwise spontaneous polymerization will occur. The solution was passed through a basic alumina (Merck, Grade-I) column (typically $\phi 10 \times \mathrm{h} 30 \mathrm{~cm}$ for $40 \mathrm{~g}$ product) eluted with dry chloroform in order to remove unreacted methacryloyl chloride and lithium chloride precipitate. Yields were typically $60-80 \%$. The structure was determined by ${ }^{1} \mathrm{H}-\mathrm{NMR}$ spectroscopy and a typical ${ }^{1} \mathrm{H}$ NMR spectrum of $\mathrm{MEO}_{7}$ is shown in Figure 1 with the synthetic procedure.

Other Chemicals. Organic solvents were distilled, stored over a molecular sieve-4A and redistilled before use.

\section{Preparation of Polymeric Solid Electrolyte Films}

A chloroform solution of oligo(oxyethylene) methacrylate was evaporated at room temperature with continuous addition of dry methanol. A given amount of sodium methacrylate and $1 \mathrm{~mol} \%$ amount (in respect to the
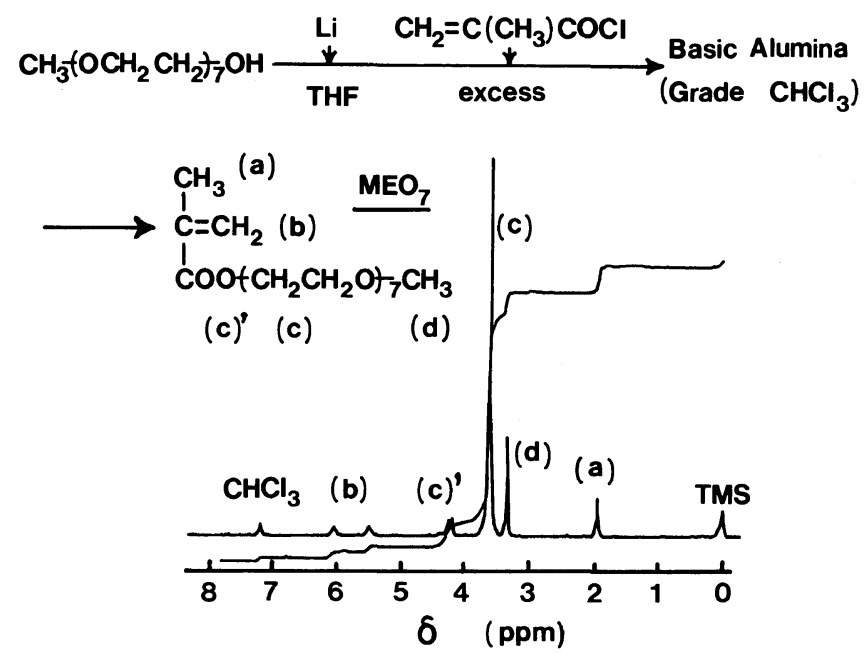

Figure 1. Synthetic scheme and ${ }^{1} \mathrm{H}$ NMR spectrum of $\mathrm{MEO}_{7}$. 
total vinyl monomers) of 2,2'-azobisisobutyronitrile were added to the resulting methanolic solution. The mixture was developed on a Teflon ${ }^{\circledR}$ plate and allowed to evaporate under dry nitrogen flow at $60^{\circ} \mathrm{C}$ for $20 \mathrm{~h}$ over $\mathrm{P}_{2} \mathrm{O}_{5}$. The remaining product on Teflon ${ }^{\circledR}$ plate was further evacuated at $80^{\circ} \mathrm{C}$ for $15 \mathrm{~h}$ in order to perform both thermal polymerization and complete drying.

\section{Measurements}

All measurements were carried out under dry argon atmosphere to avoid moisture at the given temperatures.

\section{Conductivity Measurement}

Stainless steel electrodes were used for ac (1 Volt) or dc (3 Volt) conductivity measurements. Temperature dependence of the conductivity was measured in thermally controlled apparatus under dry argon atmosphere by ac measurement technique from 0 to $80^{\circ} \mathrm{C}$. Details of instrumentation were described previously. ${ }^{17}$ The ac ionic conductivity was calculated from the complex impedance plots $^{21}$ with computer curve fitting.

\section{Differential Scanning Calorimetry}

Thermal history of film samples was analyzed by a differential scanning calorimeter (SEIKO, Model SSC-580, DSC-10) under a dry argon atmosphere. Scanning speed was set to $8 \mathrm{~K} \mathrm{~min}^{-1}$ and measurements were carried out six times for each sample.

\section{RESULTS AND DISCUSSION}

$\mathrm{P}\left(\mathrm{MEO}_{7}-\mathrm{MANa}\right)$ films were transparent or semi-transparent with good processibility and were insoluble in any organic solvents. $\mathrm{MEO}_{7}$ caused gelation through solution polymerization when it was kept over $4 \mathrm{~mol}^{\circ} \%$ at $60^{\circ} \mathrm{C}$ in THF. Although $\mathrm{PMEO}_{7}$ was obtained by homogeneous solution polymerization, it was a highly viscous liquid. It is therefore difficult to prepare thin film by casting. By such a reason, the authors applied "cast polymerization technique" to prepare thin films of $\mathrm{P}\left(\mathrm{MEO}_{7}-\mathrm{MANa}\right)$. The thickness of the films obtained was about $100 \sim 180 \mu \mathrm{m}$, but it could be made thinner by spin coating.

The sodium ionic conductivity of $\mathrm{P}\left(\mathrm{MEO}_{7}\right.$ -MANa) films was $10^{-7} \sim 10^{-8} \mathrm{~S} \mathrm{~cm}^{-1}$ at $25^{\circ} \mathrm{C}$ (Figure 2). $\mathrm{P}\left(\mathrm{MEO}_{7}-\mathrm{MANa}\right)$ systems

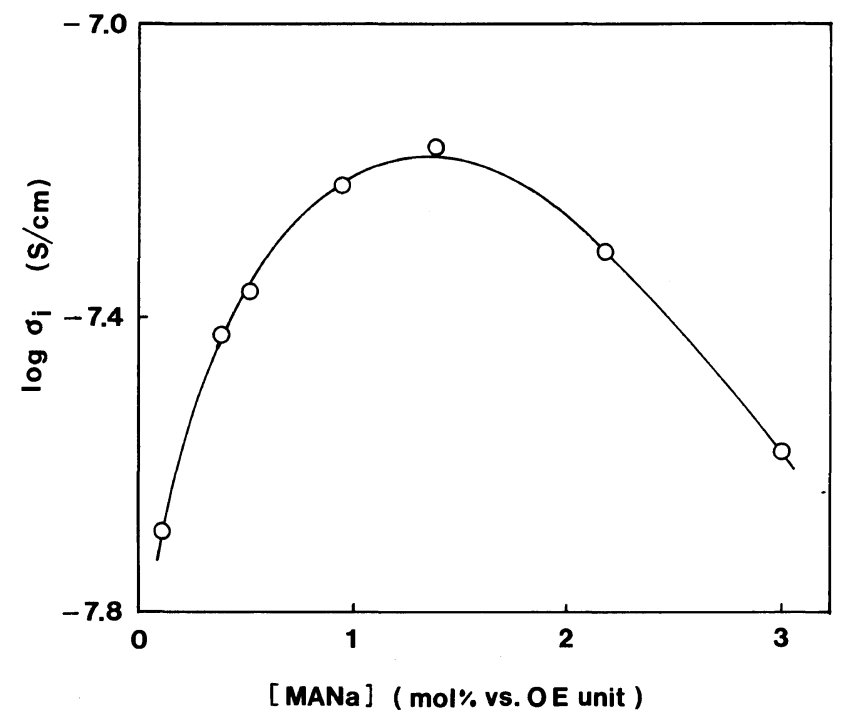

Figure 2. Dependence of the ac $(1 \mathrm{~V})$ ionic conductivity of $P\left(M^{2} O_{7}-M A N a\right)$ films on salt content at $25^{\circ} \mathrm{C}$. 
were ohmic conductors at the potential applied from 0.5 to $4.0 \mathrm{~V}$. The subsequent ac measurements were carried out at an electrode potential of $1 \mathrm{~V}$. This conductivity depended on the MANa content and reached a maximum at $[\mathrm{MANa}]=1.3 \mathrm{~mol}^{\circ} \%$ ( $v s . \mathrm{OE}$ unit) (Figure 2). The increase of ionic conductivity at low MANa content was probably due to the increase of the carrier number by adding the MANa content. Compared with $\mathrm{PMEO}_{7}$-alkali metal salt $\left(\mathrm{MSCN}^{22}\right.$, $\mathrm{MClO}_{4}$ ) hybrid systems, the lower conductivity of this may be attributed to the higher dissociation energy of salt (ca. $\mathrm{NaClO}_{4}=$ $648 \mathrm{~kJ} \mathrm{~mol}^{-1}, \quad \mathrm{NaSCN}=682 \mathrm{~kJ} \mathrm{~mol}^{-1}, \mathrm{CH}_{3}-$ $\mathrm{COONa}=763 \mathrm{~kJ} \mathrm{~mol}^{-1}$ ). The dissociation energy of PMANa was therefore estimated to be the same as $\mathrm{CH}_{3} \mathrm{COONa}$. It is clear that the solubility of $\mathrm{MANa}$ to $\mathrm{MEO}_{7}$ was evaluated from $\mathrm{X}$-ray diffraction analysis. Although in case of $\mathrm{PMEO}_{7}-\mathrm{LiClO}_{4}$ hybrid film, the crystalline structure was not found in the system with a concentration of [Li$\left.\mathrm{ClO}_{4}\right]>15 \mathrm{~mol} \%$ (vs. OE unit), X-ray diffraction peaks in $\mathrm{P}\left(\mathrm{MEO}_{7}-\mathrm{MANa}\right)$ were found in the films containing more than 0.5 mol $\%$ MANa. The broad diffraction peak at $2 \theta=10-30^{\circ}$ probably corresponded to the homogeneously polymerized part of $\mathrm{P}\left(\mathrm{MEO}_{7}-\right.$ MANa) because this peak was found for neither $\mathrm{P}\left(\mathrm{MEO}_{7}\right)$ film, PMANa, nor MANa. The sharp peak at $2 \theta=32^{\circ}$ might correspond to MANa or P(MANa) which had a diffraction peak at the same scattering angle. These data suggest that the solubility of MANa to $\mathrm{MEO}_{7}$ is lower than that of $\mathrm{LiClO}_{4}$, and this relatively poor solubility reflect the higher dissociation energy of MANa.

Time dependence of the dc ionic conductivity of $\mathrm{P}\left(\mathrm{MEO}_{7}-\mathrm{MANa}\right)$ is shown in Figure 3. Rapid decrease was observed at the initial state of the dc measurement for the cell, which was constructed from stainless steel/P( $\left.\mathrm{MEO}_{7}-\mathrm{MANa}\right) /$ stainless steel. The conductive carriers should therefore be ions. The current for dc measurement did not

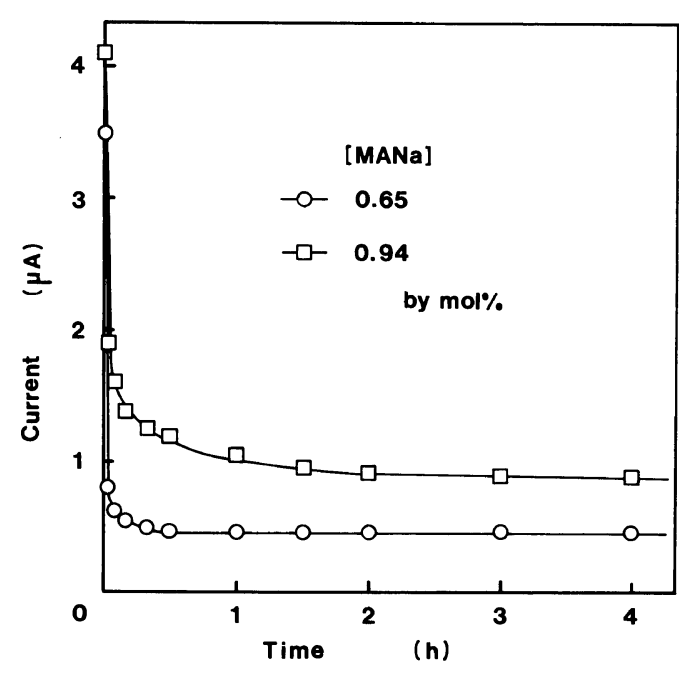

Figure 3. Time dependence of the dc $(3 \mathrm{~V})$ ionic conductivity in $\mathrm{P}\left(\mathrm{MEO}_{7}-\mathrm{MANa}\right)$ films with stainless steel electrodes at $25^{\circ} \mathrm{C}$.

reach zero in the measurement using an inactive electrode such as stainless steel. Within. this time scale for measurement, the charges passing through the film were about $1 / 100$ the total charge generated by the complete dissociation of the added salts in the film. The amount of charge passing through the film was ideally calculated by the integration of the current between time 0 and time $T_{1}$. If the added salt was dissociated completely in film, total amount of charge should also be calculated by Faraday's law. From this calculation, more than $99 \%$ the total charge certainly remained in the film. When dc voltage was applied within this time scale, the decrease of current by gradual charge separation could not be detected during the conductivity measurement. This is the reason.why the current at the steady state was observed in the $\mathrm{P}\left(\mathrm{MEO}_{7}-\mathrm{MANa}\right)$ system even using an inactive stainless steel electrode. When $\mathrm{P}\left(\mathrm{MEO}_{7}-\mathrm{MANa}\right)$ was settled between two metallic lithium electrodes and kept at room temperature for a week, the metallic luster of the lithium was maintained on the surface of lithium film side. This strongly suggests that the carrier is not a proton. Generally, 
a bi-ionic conductor, in which both the cations and anions move, showed higher conductivity rather than those for single-ionic conductors. This was clearly seen in comparison of the conductivity of $\mathrm{P}\left(\mathrm{MEO}_{7}-\right.$ MALi) with that of $\mathrm{P}\left(\mathrm{MEO}_{7}\right) /$ lithium isobutyrate hybrids. ${ }^{18}$ In the bi-ionic conductor, conductivity greatly depend on the dissociation energy of added salt. For example, when potassium, sodium or lithium was added to the films, the conductivity for the films was in the order of potassium $>$ sodium $>$ lithium. ${ }^{22}$ The conductivity of $\mathrm{P}\left(\mathrm{MEO}_{7}\right)$ / sodium iso-butyrate should therefore be higher than that of $\mathrm{P}\left(\mathrm{MEO}_{7}-\mathrm{MANa}\right)$ and $\mathrm{P}\left(\mathrm{MEO}_{7}\right) /$ lithium iso-butyrate hybrid system. If the $\mathrm{P}\left(\mathrm{MEO}_{7}-\mathrm{MANa}\right)$ film was a hybridtype bi-ionic conductor, the conductivity of this film should be higher than that of $\mathrm{P}$ $\left(\mathrm{MEO}_{7}\right)$ /sodium iso-butyrate. This is because methacrylate anion has a conjugated structure and its dissociation energy should be lower than that of iso-butyrate. In the present study, however, the conductivity of $\mathrm{P}\left(\mathrm{MEO}_{7}-\mathrm{MANa}\right)$ was much lower than that of hybrid-type bi-ionic conductor. All the results obtained strongly suggest that the sodium ion is the main carrier ion.

Temperature dependence of the ionic conductivity of $\mathrm{P}\left(\mathrm{MEO}_{7}-\mathrm{MANa}\right)$ was evaluated at temperature range from 0 to $80^{\circ} \mathrm{C}$. The temperature dependence of the conductivity is plotted in Figure 4. It is curved line rather than linear. In other words, the ionic conduction mechanism in $\mathrm{P}\left(\mathrm{MEO}_{7}-\mathrm{MANa}\right)$ film is considered to be WLF-type. The empirical Vogel-Tammann-Fulcher equation (eq 1) describes transport properties in viscous matrix. ${ }^{24}$

$$
\sigma=A \cdot T^{-1 / 2} \exp \left[-B /\left(T-T_{0}\right)\right]
$$

$T$, temperature (K); $A$, and $B$, empirical constants;

$T_{0}$, corresponding closely to glass transition temperature.

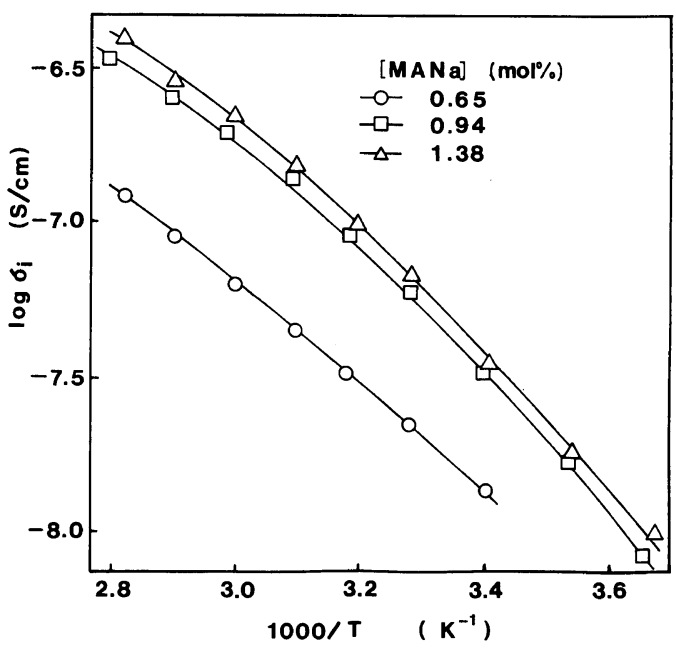

Figure 4. Temperature dependence of the ac (1 V) ionic conductivity in $\mathrm{P}\left(\mathrm{MEO}_{7}-\mathrm{MANa}\right)$ films.

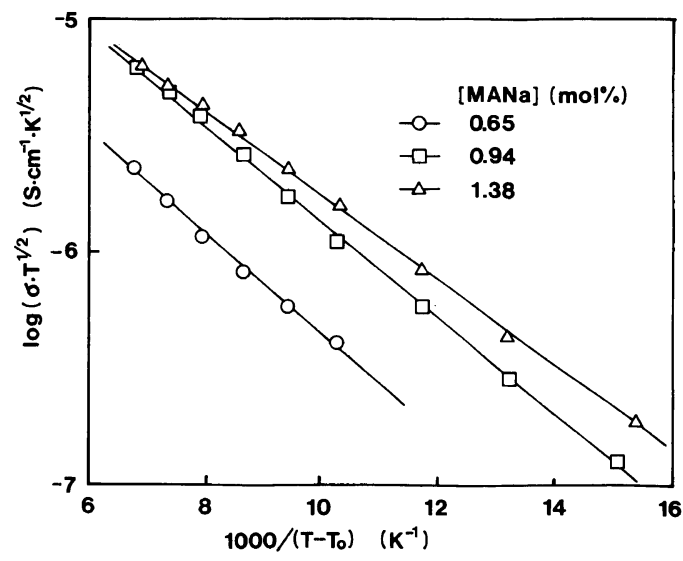

Figure 5. Vogel-Tammann-Fulcher plot of $\mathrm{P}_{\left(\mathrm{MEO}_{7}-\right.}$ $\mathrm{MANa}$ ) films.

$T_{\mathrm{g}}$ of $\mathrm{P}\left(\mathrm{MEO}_{7}-\mathrm{MANa}\right)$ film was $-67^{\circ} \mathrm{C}$ and independent of MANa content when $[\mathrm{MANa}]>0.3 \mathrm{~mol} \%$. If the ionic conduction mechanism of $\mathrm{P}\left(\mathrm{MEO}_{7}-\mathrm{MANa}\right)$ is due to WLF-type behaviour, the relationship between $\log \left(\sigma \times T^{1 / 2}\right)$ and $\left(T-T_{0}\right)^{-1}$ should be linear. In Figure 5, the Vogel-TammannFulcher plots show a good linear relationship. Namely, the ionic conduction in $\mathrm{P}$ $\left(\mathrm{MEO}_{7}-\mathrm{MANa}\right)$ system is considerably affected by the segmental motion of polymer chains. Furthermore, WLF equation (eq 2) 
Table I. WLF parameters for $\mathrm{P}\left(\mathrm{MEO}_{7}-\mathrm{MANa}\right)$ films

\begin{tabular}{crrrr}
\hline $\mathrm{mol} \%$ & \multicolumn{1}{c}{$C_{1}$} & $\begin{array}{c}C_{2} \\
(\mathrm{deg})\end{array}$ & $f_{\mathrm{g}}$ & $\begin{array}{r}\alpha_{\mathrm{f}} \times 10^{4} \\
\left(\mathrm{deg}^{-1}\right)\end{array}$ \\
\hline 0.35 & 12.15 & 23.6 & 0.036 & 15.1 \\
0.66 & 6.55 & 92.1 & 0.066 & 7.2 \\
0.80 & 7.97 & 69.7 & 0.055 & 7.8 \\
1.08 & 8.17 & 52.6 & 0.053 & 10.1 \\
1.38 & 8.54 & 58.9 & 0.051 & 8.6 \\
\hline WLF eq $^{\mathrm{a}}$ & 17.44 & 51.6 & 0.025 & 4.8 \\
\hline
\end{tabular}

a WLF empirical values.

was applied to calculate WLF parameters for the value of $\log \sigma_{i}$ at different temperatures.

$$
\log \frac{\sigma(T)}{\sigma\left(T_{\mathrm{g}}\right)}=\frac{C_{1}\left(T-T_{\mathrm{g}}\right)}{C_{2}+\left(T-T_{\mathrm{g}}\right)}
$$

$T$, temperature $(\mathrm{K}) ; T_{\mathrm{g}}$, glass transition temperature $(\mathrm{K}), \sigma(T)$, conductivity at $T \mathrm{~K} ; \sigma$ $\left(T_{\mathrm{g}}\right)$, conductivity at $T_{\mathrm{g}} ; C_{1}$ and $C_{2}, \mathrm{WLF}$ parameters.

Since $\sigma\left(T_{\mathrm{g}}\right)$ of the obtained films was too low to be measured by the usual apparatus applied in this experiment, it was calculated by extrapolation so as to make the correlation between $\left(T-T_{\mathrm{g}}\right)^{-1}$ and $\left\{\log \left[(T) /\left(T_{\mathrm{g}}\right)\right]\right\}^{-1}$ linear by computer treatment. These WLF parameters are summarized in Table I. Free volume function at $T_{\mathrm{g}}: f_{\mathrm{g}}$ and the coefficient of thermal expansion: $\alpha_{\mathrm{f}}$ were calculated by the following equations, $f_{\mathrm{g}}=1 / 2.303 \mathrm{C}_{1}$, $\alpha_{\mathrm{f}}=1 / 2.303 \mathrm{C}_{1} \mathrm{C}_{2}$, respectively. The values were comparable to the WLF empirical values $\left(C_{1}=17.4, C_{2}=51.6\right)$ with negligible deviation. This result was also supported by the above-mentioned concept about ionic conduction mechanism of $\mathrm{P}\left(\mathrm{MEO}_{7}-\right.$ MANa) system.

Acknowledgement. This work was partially supported by a Grant-in-Aid for Scientific Researches from the Ministry of Education, Science, and Culture of Japan.

\section{REFERENCES}

1. C. K. Chiang, Polym. Commun., 22, 1454 (1981).

2. T. A. Skotheim and O. Inganas, J. Electrochem. Soc., 132, 2116 (1985).

3. A. Le Mehaute, G. Crepy, G. Marcellin, T. Hamaide, and A. Guyot, Polym. Bull., 14, 233 (1985).

4. P. V. Wright, Br. Polym. J., 319, 137 (1975).

5. B. L. Papke, M. A. Ratner, and D. F. Shriver, J. Phys. Chem. Solid, 42, 493 (1981).

6. C. Berthier, W. Gorecki, M. Minier, M. B. Armand, J. M. Chabagno, and P. Riguad, Solid State Ionics, 11, 91 (1983).

7. R. Dupon, B. L. Papke, M. A. Ratner, D. H. Whitmore, and D. F. Shriver, J. Am. Chem. Soc., 104, 6247 (1982).

8. J. E. Weston and B. C. H. Steel, Solid State Ionics, 7, 81 (1982).

9. M. Watanabe, M. Togo, K. Sanui, N. Ogata, T. Kobayashi, and Z. Ohtaki, Macromolecules, 17, 2908 (1984).

10. D. J. Bannister, G. R. Davies, I. M. Word, and J. E. McIntyre, Polymer, 25, 1600 (1984).

11. D. W. Xia, D. Soltz, and J. Smid, Solid State Ionics, 14, 85 (1984).

12. P. M. Blonsky, D. F. Shriver, P. Austin, and H. R. Allcock, J. Am. Chem. Soc., 106, 6854 (1984).

13. C. K. Chiang, G. T. Davis, C. A. Harding, and T. Takahashi, Macromolecules, 18, 825 (1985).

14. E. Tsuchida, H. Ohno, and K. Tsunemi, Electrochim: Acta, 28, 591, 833 (1983).

15. E. Tsuchida, H. Ohno, K. Tsunemi, and N. Kobayashi, Solid State Ionics, 11, 227 (1983).

16. K. Shigehara, N. Kobayashi, and E. Tsuchida, Solid State Ionics, 14, 85 (1984).

17. N. Kobayashi, M. Uchiyama, K. Shigehara, and E. Tsuchida, J. Phys. Chem., 89, 987 (1985).

18. N. Kobayashi, M. Uchiyama, and E. Tsuchida, Solid State Ionics, 17, 307 (1985).

19. D. J. Bannister, G. R. Davies, I. M. Word, and J. E. McIntyre, Polymer, 25, 1291 (1984).

20. L. C. Hardy and D. F. Shriver, J. Am. Chem. Soc., 107, 3823 (1985).

21. K. S. Cole and R. H. Cole, J. Chem. Phys., 9, 341 (1941).

22. N. Kobayashi, H. Ohno, and E. Tsuchida, Nippon Kagaku Kaishi, 441 (1986).

23. M. L. Williams, R. F. Landel, and J. D. Ferry, J. Am. Chem. Soc., 77, 3701 (1955).

24. (a) H. Vogel, Phys. Z., 22, 645 (1921); (b) V. G. Tammann and W. Hesse, Z. Anorg. Allg. Chem., 156, 245 (1926); (c) G. C. Fulcher, J. Am. Chem. Soc., 8, 339 (1925). 